\title{
Performance of Quercus suber L. at nursery stage—application of two bio-inoculants under two distinct environments
}

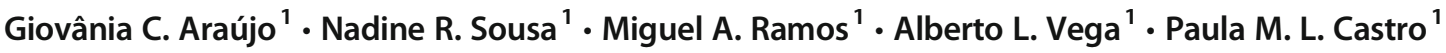

Received: 28 July 2017 / Accepted: 28 January 2018 / Published online: 8 March 2018

(C) The Author(s) 2018. This article is an open access publication

\begin{abstract}
- Key message Despite the fact that the technique of application of bioinoculants improved the quality of Quercus suber $\mathrm{L}$. seedlings produced in nurseries, these benefits are dependent on the ecological conditions of the site and the composition of the applied inoculum, which interferes with the profile of the local fungal community.

- Context Quercus suber L. plays a key ecological and socio-economical role in the Iberian Peninsula. Symbiotic ectomycorrhizal fungi-ECM are crucial partners of several tree species, and assessing the efficacy of bioinoculants at nursery stage helps devising tools to increase plant resilience.

- Aims The aim of this study was to compare the effects of two inocula formulations of mixed ECM fungi and bacteria on the quality of seedlings produced in two forest nurseries, differing in environmental conditions and forest embedment.

- Methods Quercus suber L. seedlings were inoculated with a commercial product containing Pisolithus tinctorius (Pers) Coker \& Couch, Scleroderma sp., and six bacterial species and with a non-commercial fungal and bacterial dual inoculum (Suillus granulatus (L.) Roussel + Mesorhizobium sp.). Biometric and nutritional parameters and morphological quality indexes were determined on seedlings. The ECM community was assessed by denaturing gradient gel electrophoresis and cloning-sequencing. - Results In both nurseries, the seedling quality index in inoculated was up to 2-fold higher than in non-inoculated seedlings. Plant biomass differed significantly among nurseries. The inoculum influenced the profile of the fungal community. S. granulatus and P. tinctorius persisted for 6 months in the inoculated seedlings.

- Conclusion The nursery ecosystem influenced plant growth. Inoculation treatments increased plant performance; however, the dual inoculum resulted in more consistent improvements of $Q$. suber at nursery stage, highlighting the importance of inocula selection.
\end{abstract}

Keywords Ectomycorrhizal fungi · Suillus granulatus $\cdot$ PGPB $\cdot$ Dickson Quality Index · Oak

\section{Handling Editor: Ana Rincón}

Contribution of the co-authors Giovânia C. Araújo: Experimental follow-up, sampling and data collection and analysis and writing the manuscript.

Nadine R. Sousa: Experimental design, supervision of the work and cowriting of the manuscript.

Miguel A. Ramos: Conduction of the experiment and supervision of data collection.

Alberto L. Vega: Collaboration in data collection.

Paula M.L. Castro: Experimental design, coordination of the research project, and supervision of the manuscript.

Paula M. L. Castro

plcastro@porto.ucp.pt

1 Escola Superior de Biotecnologia, Rua Arquiteto Lobão Vital, Universidade Católica Portuguesa, $\mathrm{CBQF}$ - Centro de Biotecnologia e Química Fina-Laboratório Associado, Apartado 2511, 4202-401 Porto, Portugal

\section{Introduction}

Quercus suber L. is the mainstay of multiple-use agroforestry systems with great socio-economic and environmental value in the western Mediterranean region. For this reason, the mortality events that have been affecting this species since the beginning of the XX century, with an increase during the 1980s (CamiloAlves et al. 2013), are a strong reason for concern. The decline of $Q$. suber is mainly attributed to diseases and pests (e.g., Phytophthora cinnamomi), to a high sensitivity to environmental factors, namely, drought (Chirino et al. 2008; Trubat et al. 2010; Costa and Madeira 2011) or a combination of several factors, including the above (Camilo-Alves et al. 2013). Natural regeneration from seed is not always successful, and the survival rate of transplanted seedlings is often low (Sebastiana et al. 2013). Under this context, it is of utmost importance to explore the 
potential of the association between $Q$. suber and beneficial microbial symbionts which are known to be crucial to the host plant under unfavorable conditions.

Ectomycorrhizal (ECM) fungi form symbiotic associations with the majority of forest trees and are crucial for their nutrition and water acquisition (Moeller et al. 2014). They are also strong competitors against soil-borne root parasites, providing both mechanical (Frey-Klett et al. 2005) and biochemical (Cairney and Chambers 2013) protection against pathogens (Perrin and Garbaye 1983). Their relevance can be seen from a young age since the success of seedling transplantation has been pointed out to be strongly related with increased association with ECM fungi (Dickie et al. 2002). Thus, in the quest to improve the quality and field resilience of nursery-produced $Q$. suber seedlings, the association with ectomycorrhizal fungi should be a forefront strategy. However, in nature, trees may be colonized by multiple species (Trappe 1977; Morris et al. 2008) and much remains to be understood about this association (Garcia et al. 2015). The choice of fungal inoculants seems to be a crucial factor since not all are beneficial to plant development (Sousa et al. 2012) or persist in the root system after field transplantation (Franco et al. 2014).

Bacteria are ubiquitous inhabitants of soil, water, and plants (internal and externally). Some bacteria are known to be beneficial to plants (plant growth-promoting rhizobacteria (PGPR)) through direct mechanisms such as the production of phytohormones or indirect such as biocontrol agents (Ahemad and Kibret 2014). They also form synergies with ECM fungi (mycorrhization helper bacteria (MHB)) (Hrynkiewicz and Baum 2011; Bhattacharyya and Jha 2012; Owen et al. 2014) by stimulating mycelial extension, increasing root-fungus contact, and reducing the impact of adverse environmental conditions on the mycelium of the mycorrhizal fungi (Frey-Klett et al. 2007). As such, the combination of ECM fungi and bacteria for improved plant quality has great potential in forestry.

Here, we present a study on the inoculation of $Q$. suber seedlings with two bio-inoculants, a commercial mix and a non-commercial inoculum produced in our laboratories. The commercial product, PHC Ecto-Injectable Pt. (Plant Health Care), contained a blend of two fungal symbionts often found in $Q$. suber ecosystems, Pisolithus tinctorius (Pers) Coker \& Couch and Scleroderma sp. (Azul et al. 2010), as well as six beneficial rhizosphere bacterial species belonging to the Bacillus and Streptomyces genera. The noncommercial product consisted in two indigenous microorganisms from northern Portugal, Suillus granulatus (L.) Roussel and Mesorhizobium sp. S. granulatus was chosen for its mycorrhization skills, whereas the bacterium, Mesorhizobium sp., was selected based on its potential as PGPR (Pereira et al. 2014). The objective was thus to compare the effects of the two bio-inoculants in seedling development after 9-month cultivation at the nursery, using procedures that could easily be adopted by a nursery. Moreover, to evaluate the performance consistency of the inocula under different conditions, the assays were conducted in two forest nurseries located in Amarante and Buçaco.

\section{Material and methods}

\subsection{Inoculation of Q. suber seedlings}

Two bio-inoculants were tested, a commercial inoculum, PHC Ecto-Injectable (Plant Health Care), and one produced at ESBUCP. The commercial product contained a blend of two ectomycorrhizal fungi, Pisolithus tinctorius and Scleroderma sp., and six beneficial rhizosphere bacterial species belonging to the Bacillus and Streptomyces genera. The ESB-UCP inoculum consisted in two microorganisms, S. granulatus (Sgran01) and Mesorhizobium sp. (isolate 3A12). S. granulatus was isolated from a fruitbody collected in Macedo de Cavaleiros and was chosen for its good mycorrhization skills shown on preliminary mycorrhization studies conducted with $Q$. suber. Mesorhizobium sp. was isolated from soil collected in Estarreja and was chosen for its plant-growth promoting potential, namely, its ability to produce substances such as indole-acetic acid, siderophores, and 1-aminocyclopropane-1-carboxylate (ACC) deaminase (Pereira et al. 2014).

The inoculation with the ESB-UCP inoculum, hereafter referred to as $\mathrm{SgB}$, consisted in applying $5 \mathrm{ml}$ of a mycelial suspension of $S$. granulatus (ca. $170 \mathrm{mg}$ of fresh weight) and $5 \mathrm{ml}$ of the Mesorhizobium sp. suspension close to the root system of 1-month-old Q. suber seedlings. The fungal suspension was prepared immediately before application by blending fungal mycelium, which had been grown for 3 weeks on MMN medium, into sterile deionized water. The Mesorhizobium sp. suspension was obtained as described in Sousa et al. (2015). Briefly, the inoculum was obtained by growing a pure culture in TSB $\left(150 \mathrm{rpm}, 28{ }^{\circ} \mathrm{C}\right)$ until it reached an OD of $0.8\left(10^{8} \mathrm{CFU} / \mathrm{ml}\right)$. The suspension was then centrifuged for $20 \mathrm{~min}$ at $8000 \mathrm{rpm}$ and washed three times with saline solution $(0.85 \% \mathrm{NaCl})$ before being resuspended in saline solution. The commercial product, hereafter referred to as Mix, was prepared according with the manufacturer's instructions, and $5 \mathrm{ml}$ was applied close to the root system of 1-month-old $Q$. suber seedlings. A control comprising noninoculated seedlings was also established.

\subsection{Greenhouse experimental design}

The inoculation treatments Control, $\mathrm{SgB}$, and Mix were cultivated in trays with $250-\mathrm{cm}^{3}$ cells in two forest nurseries, Amarante $\left(41^{\circ} 16^{\prime} 42.10^{\prime \prime} \mathrm{N}, 8^{\circ} 03^{\prime} 59.89^{\prime \prime} \mathrm{W}\right)$ and Buçaco (4022' 33.92" N, $\left.8^{\circ} 51^{\prime} 49.93^{\prime \prime} \mathrm{W}\right)$, northern Portugal, between April and October 2014. The substrate consisted in a mixture of peat (NPK $0.8 \mathrm{~g} / \mathrm{l})$ and perlite $(5: 1)$. The same 
substrate was used in both nurseries and no additional fertilization was carried out. The substrate was not autoclaved since this work had a very practical approach, and the use of sterile substrate would not be economically feasible for commercial forest nurseries. In each nursery, seeds were germinated in trays of $250-\mathrm{cm}^{3}$ cells, inside a greenhouse where temperature ranged from 10 to $25{ }^{\circ} \mathrm{C}$ and relative humidity from 50 to $80 \%$. Two weeks after germination, seedlings were transferred to the outside, and were covered by a shade cloth, where they remained until the end of the experiment. Seedlings were visually inspected for contaminants before inoculation. Onehundred replicates per inoculation treatment were performed. Plants were watered by microsprinklers with a frequency adjusted to the environmental conditions. Seeds used in both nurseries were of the same provenance, Alcácer do Sal, and were certified by Centro Nacional de Sementes Florestais (CENASEF).

\subsection{Plant sampling and analysis}

After 6 months, a subsample of 20 plants from each treatment (a total of 60 from each nursery) was randomly selected, carefully removed from the trays, and transported to the laboratory where shoot height, root length, and stem diameter were measured and the fresh weight of shoots and roots were determined. Shoot height and root length were measured with a ruler and stem diameter with a pachymeter. The root system was carefully washed to remove adhering substrate, and the percentage of mycorrhization was calculated according to the method described in Brundrett et al. (1996). Six plants per inoculation treatment were evaluated using a stereomicroscope (SZ30, Olympus, Japan). ECM root tips were collected for molecular studies. Shoots and roots were dried at $70^{\circ} \mathrm{C}$ for $48 \mathrm{~h}$. After weighted, the samples were ground, digested according to Novozamsky et al. (1983), and the concentration of nitrogen $(\mathrm{N})$ and phosphorus $(\mathrm{P})$ in the shoots and roots determined by colorimetry (Unicam, Helios Gamma, Cambridge, UK) (Walinga et al. 1989).

\subsection{Morphological indexes and nutrient use efficiency}

Seedling quality indexes are considered to be good indicators of field performance and resistance (Ahmadloo et al. 2012). Using the biometric data, the slenderness quotient (SQ) (Thompson 1985), the Dickson Quality Index (DQI) (Dickson et al. 1960), and total dry biomass increment (BI) (Dhindwal et al. 1991) were determined using Eqs. (1), (2), and (3). From the total nitrogen (N) and phosphorus $(\mathrm{P})$ contents, $\mathrm{N}$ and $\mathrm{P}$ use efficiency, NUE, and PUE $\left(\mathrm{g}^{2} \mathrm{mg}^{-1}\right)$ were determined according to Siddiqi and Glass (1981) (Eq. 4).
$\mathrm{SQ}=$ height $[\mathrm{cm}] /$ diameter $[\mathrm{mm}])$

$\mathrm{DQI}=$ shoot dry mass $[\mathrm{g}]+\operatorname{root} \operatorname{dry} \operatorname{mass}[\mathrm{g}] /(\mathrm{SQ})$ $+($ shoot dry mass $[\mathrm{g}] /$ root dry mass $[\mathrm{g}])$

$\mathrm{BI}(\%)=$ total dry mass - total dry mass control/total dry mass control $\times 100$

$\mathrm{NUE}=\left(\left[(\text { total drymass })^{2} /(\right.\right.$ total plant nutrient content $\left.\left.)\right]\right)$

\subsection{Fungal community established}

Ectomycorrhizal root tips were extracted from each inoculation treatment and maintained frozen $\left(-20^{\circ} \mathrm{C}\right)$, in $2 \times$ cetyltrimethyl bromide-ammonium $(\mathrm{CTAB})$ until analysis. The root tips from each treatment were assembled together (ca. 150 root tips per treatment). They were selected from six plants, 25 tips per plant, taking into consideration the different morphotypes found and the DNA extracted by grinding the samples with liquid $\mathrm{N}$ and subsequently using the Power Soil DNA Isolation Kit (MoBio Laboratories). The PCR amplification of the internal transcribed spacer (ITS) region of ribosomal DNA was performed by nested PCR (Sousa et al. 2012). The nested PCR was made using ITS1F-GC and ITS2 primers. Denaturing gradient gel electrophoresis (DGGE) was performed on a DCodeTM Universal Mutation Detection System (Bio-Rad Laboratories, Hercules, CA, USA). Samples containing approximately $800 \mathrm{ng}$ of nested-PCR amplicons were run for $16 \mathrm{~h}$ at $60{ }^{\circ} \mathrm{C}$, in a $8 \%(w / v)$ polyacrylamide gel $(37.5: 1$, acrylamide/bis-acrylamide) using a denaturing gradient ranging from 20 to $60 \%$ at $80 \mathrm{~V}$ (Sousa et al. 2015).

To identify the predominant ECM species present in the two nurseries, analyses of molecular cloning of relevant samples were performed according to Sousa et al. (2014). Briefly, the purified PCR fragment was ligated into the vector pNZY28 of NZY-A PCR cloning kit (Nzytech). Eleven white colonies from each inoculation treatment were amplified using vector primers M13PUC forward and reverse (Stab-Vida, Portugal). Screening of the clone library was assessed by restriction fragment length polymorphism (RFLP) analysis using the restriction enzymes Taq I and Hinf I (Bioron). PCR products of clones revealing different profiles were purified (PCR and Gel Band Purification Kit, GRISP, Portugal) and sequenced (Stab-Vida, Portugal). The operational taxonomic units (OTUs) were defined using Bioedit software (Hall 1999), considering a $97 \%$ sequence similarity threshold. For each OTU, the ITS sequence was analyzed for similarity with other 
sequences in BLASTn through the NCBI database, to determine the closest sequence identity.

The Bands generated by DGGE were analyzed through the program BioNumerics (BioNumerics version 6.6, Applied Mathematics, Belgium). The DGGE profiles were compared against a DGGE reference marker made with the formerly identified clones. The results were represented as a cluster diagram using unweighted pair-group method with arithmetic average (UPGMA) method and Jaccard coefficient.

\subsection{Statistical analyses}

The obtained data were tested for normality and homogeneity of the variances. ECM percentages were square root transformed. A two-way ANOVA was performed for each dependent variable versus the independent variables inoculation (Control, $\mathrm{SgB}$, and Mix) and nursery (Amarante and Buçaco). In Amarante, from April to October, the maximum temperature varied from 22 to $31^{\circ} \mathrm{C}$, while in Buçaco, it was between 23 and $25{ }^{\circ} \mathrm{C}$. The relative atmospheric humidity registered in this period was between 43 to $98 \%$ in Amarante and 44 to $91 \%$ in Buçaco. Given that strong interactions among factors were observed, a one-way ANOVA was then conducted for each dependent variable versus the independent variables (inoculations). When the $F$ value was significant $(P<0.05)$, the Tukey's multiple range test was used to detect differences between inoculation treatments within each nursery and Student's $t$ test to differences between nurseries for each inoculation treatment. In order to detect underlying patterns on the influence that the independent variables (nursery and/or inoculation treatment) may have on plant growth, the data on height, root length, diameter, and shoot and root dry mass were used to perform a principal component analysis (PCA) conducted with varimax rotation. The Kaiser-MeyerOlkin measurement verified the sample adequacy for analysis $(\mathrm{KMO}=0.770)$ and Bartlett's sphericity test (chi-square with $P<0.001)$. These analyses were performed using the SPSS 17.0 software package (SPSS Inc., Chicago, IL, USA).

\subsection{Data availability}

This manuscript has no associated data or data archiving is not mandated

\section{Results}

\subsection{Plant growth}

In both nurseries, inoculation had an overall positive effect on plant development. In Amarante, the shoot height of seedlings inoculated with $\mathrm{SgB}$ was 1.1- and 1.5-fold higher than the Mix and Control treatments, respectively, while in Buçaco, a 1.2-fold increase was observed. The dual inoculum $\mathrm{SgB}$ excelled among inoculation treatments in Buçaco, showing higher average values for almost all growth parameters, namely, shoot dry mass, root dry mass, and stem diameter, with an increase of 1.29-, 1.35-, and 1.16-fold compared to the Mix, and a 1.52-, 1.58-, and 1.26-fold compared to the Control $(P<0.05)$. In Amarante, $\mathrm{SgB}$ and Mix performed similarly, with inoculated plants showing superior performance than the control for most growth parameters (Fig. 1). Seedlings with the same inoculation treatment performed differently in each nursery for the majority of the parameters studied, except for stem diameter $(\mathrm{SgB})$ and root dry mass $(\mathrm{SgB}$ and Control), where no difference was observed between Amarante and Bucaco $(P>0.05)$ (Table 1) (Fig. 1).

\subsection{Morphological indices}

The DQI presented values above 0.2 for all treatments. In Amarante, the Mix treatment presented significantly higher values than the $\mathrm{SgB}$ and Control, but in Buçaco, $\mathrm{SgB}$ led to higher average values that significantly differed from non-inoculated and from seedlings inoculated with Mix. Between nurseries, control and Mix of Buçaco showed a statistically significant lower average values than what was found in the nursery of Amarante (Table 2).

The Slenderness Quotient (SQ), which evaluates shoot development, was significantly greater in seedlings inoculated with $\mathrm{SgB}$ in Amarante $(P<0.05)$, whereas in Buçaco, no significant difference between inoculation treatments occurred. Moreover, all inoculation treatments differed statistically between nurseries (Table 2).

Inoculated seedlings had a higher dry biomass than the Control; however, the total dry biomass increment was not significantly different between the $\mathrm{SgB}$ and Mix treatments in both nurseries (Table 2).

\subsection{Nitrogen and phosphorus}

Larger PUE and NUE were detected in inoculated versus non-inoculated seedlings (Fig. 2e, f). However, seedlings inoculated with $\mathrm{SgB}$ were superior in the two nurseries, with values $2.4-$ and 1.8-fold higher for NUE than the control and Mix treatment, respectively $(P<0.05)$. For PUE, in Amarante, seedlings inoculated with $\mathrm{SgB}$ were 2.8 -fold higher than Control (Fig. 2e). In Buçaco, the $\mathrm{SgB}$ treatment presented PUE values 2.5and 2.6-fold higher than control and Mix, respectively $(P<0.05)$. Between nurseries, only the control plants 

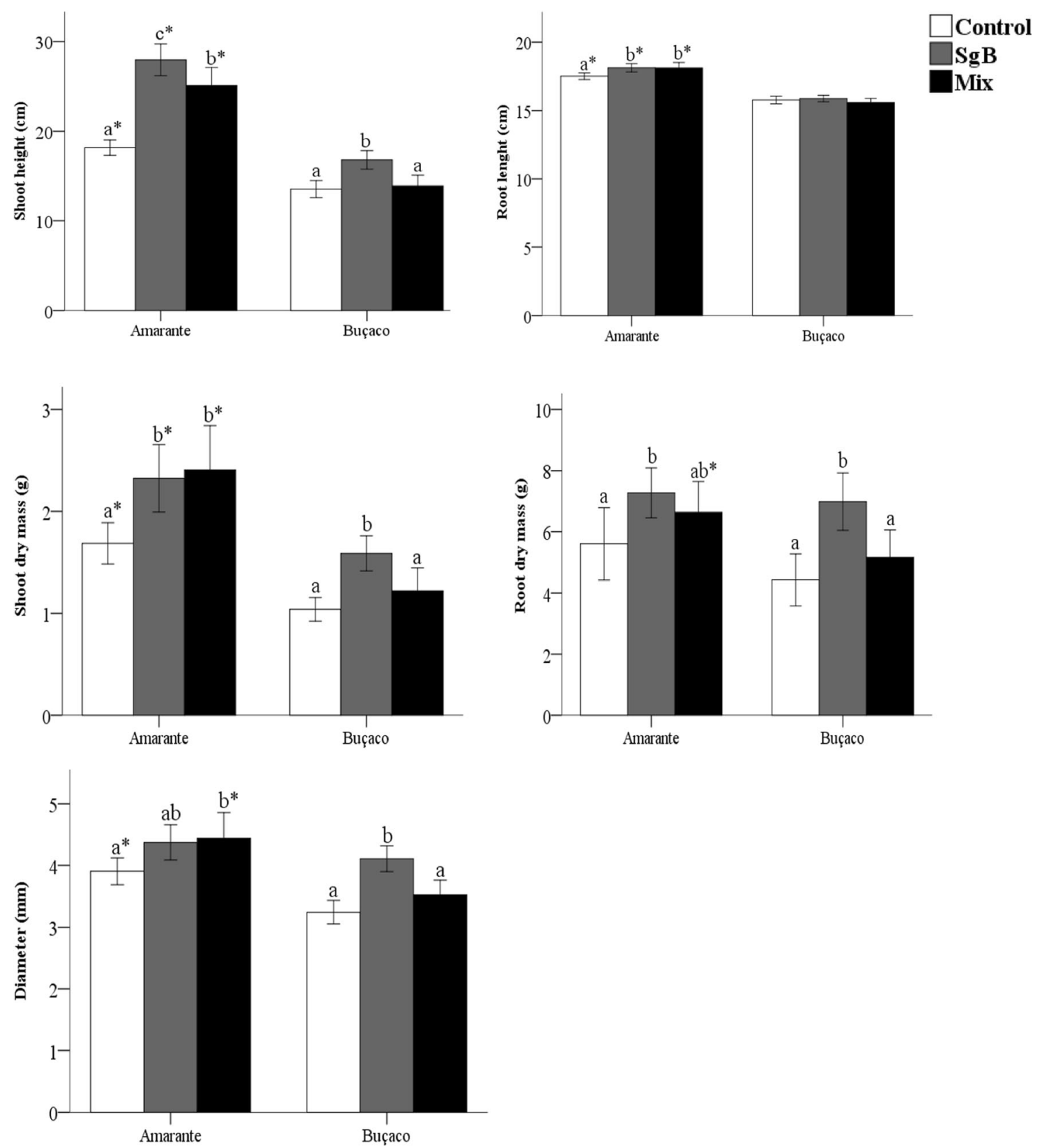

Fig. 1 Biometric traits of seedlings of $Q$. suber inoculated with $S$. granulatus + Mesorhizobium sp., commercial Mix and noninoculated. Each bar represents the mean with $95 \%$ confidence interval. For each nursery, different letters indicate significant differences

according to Tukey's multiple range test at $P<0.05$. Asterisks mean differences between nurseries for a given inoculation treatment by Student's $t$ test at $P<0.05 . N=120$

Table $1 F$-statistics of two-way ANOVA on the effects of inoculation (Control, $\mathrm{SgB}$, Mix) and nursery (Amarante and Buçaco) for the dependent variables studied shoot height (SH), root length $(\mathrm{RL})$, shoot and root dry mass (SDM, RDM), stem diameter $(D)$, \% mycorrhizal colonization $(\mathrm{ECM})$, Dickson Quality Index (DQI), Slenderness Quotient (SQ), efficiency of N use (NUE), and P (PUE)

\begin{tabular}{lcllllllllll}
\hline Source of variation & $\mathrm{SH}$ & $\mathrm{RL}$ & $\mathrm{SDM}$ & $\mathrm{RDM}$ & $D$ & $\mathrm{ECM}(\%)$ & $\mathrm{DQI}$ & $\mathrm{SQ}$ & $\mathrm{NUE}$ & $\mathrm{PUE}$ \\
\hline Inoculation & $49.41^{* * *}$ & $2.33(\mathrm{NS})$ & $6.93^{* *}$ & $10.95^{* * *}$ & $13.47 * * *$ & $0.44(\mathrm{NS})$ & $15.16^{* * *}$ & $38.15^{* * *}$ & $10.18^{* * *}$ & $9.63^{* *}$ \\
Nursery & $281.0^{*}$ & $194.2 * * *$ & $54.47 * * *$ & $7.07 *$ & $33.82^{* * *}$ & $23.0^{* * *}$ & $11.29 * *$ & $0.004(\mathrm{NS})$ & $6.45^{*}$ & $3.78(\mathrm{NS})$ \\
Inoculation and nursery & $16.50^{*}$ & $4.11^{*}$ & $6.91 * *$ & $1.78(\mathrm{NS})$ & $3.23 *$ & $3.7 *$ & $7.49 * *$ & $42.4 * * *$ & $0.23(\mathrm{NS})$ & $0.48(\mathrm{NS})$ \\
\hline
\end{tabular}

$N=20$ (*Significant at $P<0.05, * *$ significant at $P<0.01, * * *$ significant at $P<0.001$ ) 
Table 2 Dickson Quality Index $\left(\mathrm{g} \mathrm{cm}^{-1} \mathrm{~mm}^{-1}\right)$, Slenderness Quotient $\left(\mathrm{cm} \mathrm{mm}^{-1}\right)$, and total dry biomass increment (\%)

\begin{tabular}{lllll}
\hline & Control & SGB & Mix & $F$ \\
\hline Amarante & & & & \\
$\quad$ Dickson Quality Index & $1.48 \pm 0.14 \mathrm{a}^{*}$ & $1.64 \pm 0.10 \mathrm{ab}$ & $2.07 \pm 0.18 \mathrm{~b}^{*}$ & 4.36 \\
Slenderness Quotient & $4.70 \pm 0.14 \mathrm{a}^{*}$ & $6.35 \pm 0.24 \mathrm{c}^{*}$ & $5.72 \pm 0.18 \mathrm{~b}^{*}$ & 29.84 \\
Biomass increment (\%) & - & $61.47 \pm 20.72 \mathrm{a}$ & $59.87 \pm 14.54 \mathrm{a}$ & 0.004 \\
Buçaco & & & & \\
Dickson Quality Index & $0.85 \pm 0.09 \mathrm{a}^{*}$ & $1.86 \pm 0.07$ & $1.46 \pm 0.10 \mathrm{~b}^{*}$ & 27.70 \\
Slenderness Quotient & $4.17 \pm 0.16 \mathrm{a}^{*}$ & $4.12 \pm 0.11 \mathrm{a}^{*}$ & $3.97 \pm 0.18 \mathrm{a}^{*}$ & 45.91 \\
Biomass increment (\%) & - & $62.41 \pm 18.43 \mathrm{a}$ & $38.57 \pm 12.98 \mathrm{a}$ & 1.05 \\
\hline
\end{tabular}

Different letters differed significantly according to Tukey's multiple range test at $P<0.05$ or Student's $t$ test at $P<0.05$ (biomass increment). Asterisks mean differences between nurseries for a given inoculation treatment by Student's $t$ test at $P<0.05 . N=120$ differed in the NUE, with those in Amarante being 1.57-fold higher than in Buçaco (Fig. 2f). The high concentrations of $\mathrm{P}$ and $\mathrm{N}$ in the control plants (Fig. 2a-d) did not translate into increased biomass (Fig. 1).

\subsection{ECM community analysis}

In Buçaco, Control plants showed a significantly higher mycorrhization percentage than in Amarante, with a 5fold difference. From the plants inoculated, only the Mix showed an ECM percentage higher than the Control, with a 3.12-fold increase in Amarante (Fig. 3a). The ECM percentage with $\mathrm{SgB}$, although higher in Buçaco, had no statistical difference from $\mathrm{SgB}$ in Amarante, and the ability of plants inoculated with Mix to mycorrhize was also similar in both nurseries (Fig. 3a). Dendrogram of similarity resulting from the DGGE banding profiles (Fig. 3b) clearly showed two differentiated clusters ( $35.86 \pm 3.2 \%$ of similarity). Samples from each nursery grouped together in each main cluster, showing that the ECM fungal community installed in each nursery was different; however, according to the value of the cophenetic correlation coefficient (0.64), the grouping of the samples in separate clusters was not very robust. In Buçaco, the sub-cluster composed by $\mathrm{SgB}$ and Mix presented about $55.56 \% \pm 0.0$ of similarity ( 0.68 cophenetic correlation coefficient) and shared ca. $40 \%$ of similarity with its Control. Interestingly, $\mathrm{SgB}$ and Mix samples from the nursery in Amarante shared an even lower degree of similarity $(<42 \%$ of similarity, 0.83 cophenetic correlation coefficient) (Fig. 3b).

\subsubsection{ITS clone library analysis}

Seven fungal OTUs (GenBank) belonging to phylum Basidiomycota and Ascomycota were identified.
$S$. granulatus used in the dual inoculum persisted in the root system of inoculated seedlings (Table 3). From the two fungi indicated as present in the commercial inoculum, only $P$. tinctorius was found in the root system after 9 months. Pezizales and Tomentella genera were present in five of the six inoculation treatments. A species from the Hypocreales order was found in the Mix and control in Buçaco (Table 3).

\subsection{Plant development $\times$ nursery $\times$ inoculation treatment}

According to the analysis of principal components, two components were extracted explaining $87.10 \%$ of the variation of the data. Component 1 is represented by biomass (shoot and root dry mass, diameter) and component 2 by vertical growth (shoot height and root length). The separation between nurseries is due mostly to the higher biomass in the Amarante plants (Fig. 4a). Among inoculation variables, it is observed that the inoculated plants of Amarante tend to disperse from the first to the fourth quadrant, whereas control is characterized by lower vertical growth. In Buçaco, there is a lower variance in plant growth, with the Control followed by the mix in the third quadrant, represented by lower biomass and height, while $\mathrm{SgB}$ inoculation treatment presents higher vertical growth. When the data are plotted per ECM percentage, the separation between the nurseries becomes more marked, and the plants with the highest percentage of colonization are those with the lower biomass represented in the third quadrant (Fig. 4b).

\section{Discussion}

Overall, the mixed and dual inoculation treatments promoted the growth of $Q$. suber at nursery stage. However, the 

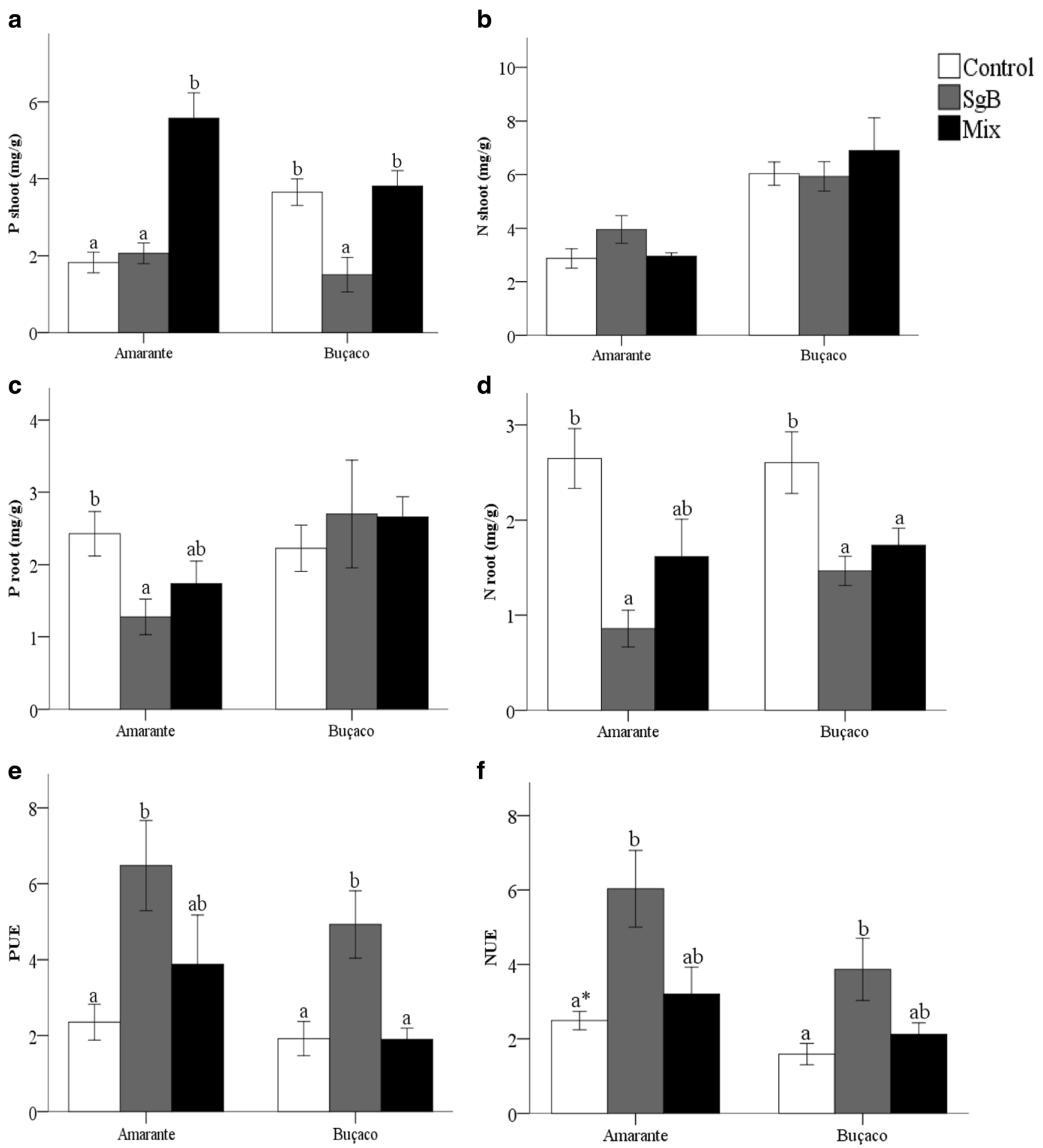

Fig. 2 Concentrations of $\mathrm{P}$ and $\mathrm{N}$ in shoot $(\mathbf{a}, \mathrm{b})$ and $\operatorname{root}(\mathbf{c}, \mathbf{d})$ and efficiency of $\mathrm{P}(\mathbf{e})$ and $\mathrm{N}(\mathbf{f})$ use. For each nursery, different letters indicate significant differences according to Tukey's multiple range test at $P<0.05$. Each bar represents the mean \pm S.E. $N=36$

treatment $\mathrm{SgB}$, composed of indigenous symbionts, was more consistent as it promoted plant growth in both nurseries, whereas the Mix was not effective in Buçaco. Seedlings grown in Amarante showed higher absolute values for most of the biometric parameters compared to Buçaco. Given that seed, substrate, and irrigation system were the same in the two nurseries and no visible symptoms of disease was detected in the plants, this difference can only be attributed to the different environmental conditions, such as temperature, humidity and light exposure, the quality of the irrigation water, and/or the pre-existing ECM community, which differed between nurseries; moreover, the effect of inoculation in the two nurseries 


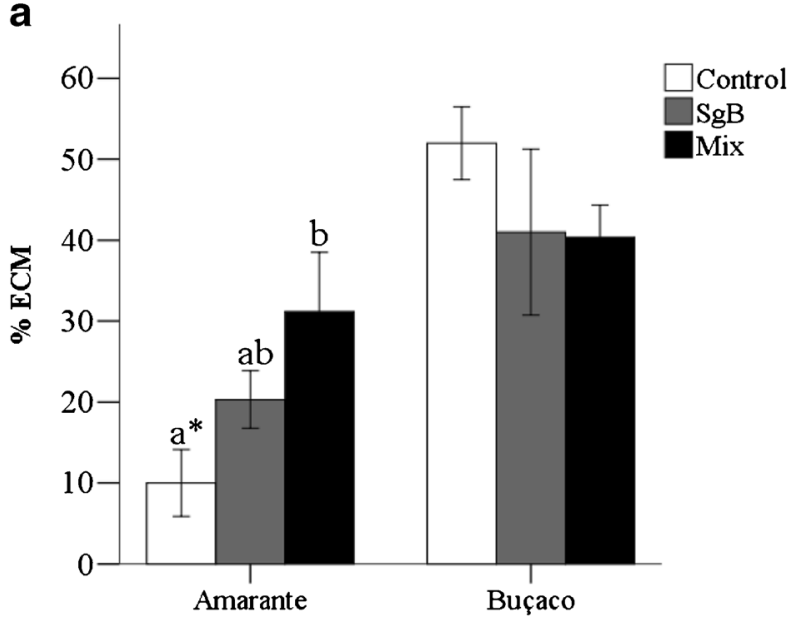

Fig. 3 Percentage of ECM fungal colonization (\%ECM) (a). Each bar represents the mean \pm S.E. For each nursery, different letters indicate significant differences according to Tukey's multiple range test at $P<0.05$. $N=36$. Asterisks mean differences between nurseries for a given inoculation treatment by Student's $t$ test at $P<0.05$. Dendrogram from UPGMA cluster analysis based on the Jaccard coefficient of ITS DGGE patterns of the DNA of fungal communities from mycorrhizal root b

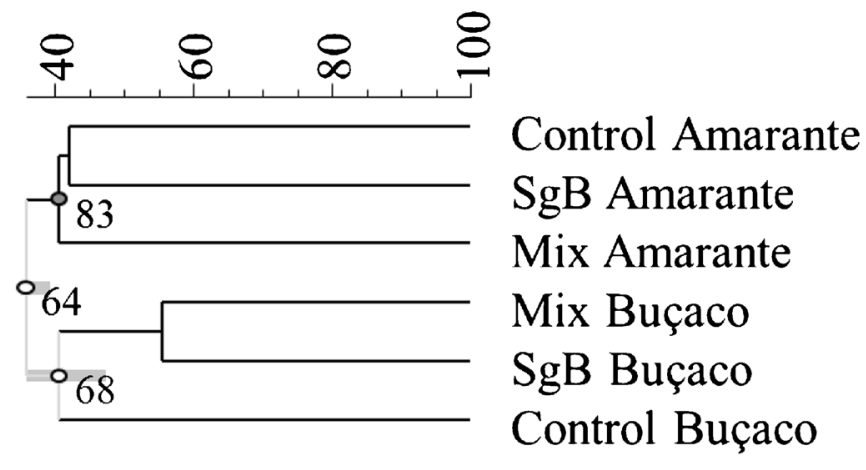

tips of Quercus suber seedlings non-inoculated (Control) and inoculated with dual inoculum ( $\mathrm{SgB}$ ) and Mix commercial inoculum (Mix), growing in two different nurseries, Amarante and Buçaco (b). The scale bar indicates the percentage of similarity. Numbers at nodes represent the cophenetic correlation coefficient values, which estimate the consistency of each sub-cluster. Gray bars at each node correspond to the standard deviation of values in that region of the similarity matrix was different as indicated by the significant interaction between the inoculation treatment and the specific nursery for the majority of biometric traits.

According to Quoreshi and Khasa (2008), the mycorrhizal inoculation may not have a direct impact on plant nutrient concentration, but the symbiosis increases the efficiency of plant in the conversion of absorbed nutrients into biomass, decreasing the concentration in the tissue due to the effect of dilution by the vegetal growth (Taub and Wang 2008). The present study corroborates this, as it is observed that plants inoculated with $\mathrm{SgB}$ in Amarante simultaneously had the best performance and the lowest $\mathrm{N}$ and $\mathrm{P}$ root concentration.

Table 3 Ectomycorrhizal fungal species detected in inoculated and non-inoculated plants of Amarante and Buçaco nurseries

\begin{tabular}{|c|c|c|c|c|c|c|c|c|c|c|}
\hline \multirow{3}{*}{$\begin{array}{l}\text { Blastn closest match } \\
\text { (NCBI/BLAST accession } \\
\text { number) }\end{array}$} & \multirow[t]{3}{*}{ Specie } & \multirow[t]{3}{*}{ Order } & \multirow[t]{3}{*}{ Phylum } & \multirow[t]{3}{*}{ Similarity $(\%)$} & \multicolumn{6}{|c|}{ ECM fungal presence } \\
\hline & & & & & \multicolumn{3}{|c|}{ Amarante } & \multicolumn{3}{|l|}{ Buçaco } \\
\hline & & & & & Control & $\mathrm{SgB}$ & Mix & Control & $\mathrm{SgB}$ & Mix \\
\hline $\begin{array}{l}\text { Pisolithus tinctorius } \\
\text { 18S rRNA HE578142.1 }\end{array}$ & P. tinctorius & Boletales & Basidiomycota & 100 & & & $\mathrm{x}$ & & & $\mathrm{x}$ \\
\hline $\begin{array}{l}\text { Tomentella clone VT135 } \\
\text { HM487022.1 }\end{array}$ & Tomentella sp. & Thelephorales & Basidiomycota & 99 & $\mathrm{x}$ & $\mathrm{x}$ & $\mathrm{x}$ & & & $x$ \\
\hline Pezizales clone P1 EF484935.1 & Pezizales sp. & Pezizales & Ascomycota & 99 & $\mathrm{x}$ & $\mathrm{x}$ & $\mathrm{x}$ & $\mathrm{x}$ & & $\mathrm{x}$ \\
\hline $\begin{array}{l}\text { Cylindrocarpon pauciseptatum } \\
\text { JF735305.1 }\end{array}$ & C. pauciseptatum & Hypocreales & Ascomycota & 98 & & & & $\mathrm{x}$ & & $\mathrm{x}$ \\
\hline $\begin{array}{l}\text { Thelephoraceae clone } \\
\text { P1 HM487022.1 }\end{array}$ & Thelephora sp. & Thelephorales & Basidiomycota & 99 & $\mathrm{x}$ & & & $\mathrm{x}$ & $\mathrm{x}$ & $\mathrm{x}$ \\
\hline $\begin{array}{l}\text { Laccaria proxima voucher } \\
\text { DQ414726.1 }\end{array}$ & L. próxima & Agaricales & Basidiomycota & 100 & $\mathrm{x}$ & $\mathrm{x}$ & & $\mathrm{x}$ & & $\mathrm{x}$ \\
\hline Hebeloma sp. EF564172.1 & Hebeloma $\mathrm{sp}$ & Agaricales & Basidiomycota & 100 & & & & $\mathrm{x}$ & $\mathrm{x}$ & $\mathrm{x}$ \\
\hline $\begin{array}{l}\text { Thelephora terrestris } \\
\text { JQ712012.1 }\end{array}$ & T. terrestris. & Thelephorales & Basidiomycota & 99 & $\mathrm{x}$ & & & $\mathrm{x}$ & $\mathrm{x}$ & $\mathrm{x}$ \\
\hline $\begin{array}{l}\text { Suillus granulatus clone } \\
\text { NS215 DQ068968.1 }\end{array}$ & S. granulatus & Boletales & Basidiomycota & 99 & & $\mathrm{x}$ & & & $\mathrm{x}$ & \\
\hline
\end{tabular}

Based on cloning data, $N=11$ 


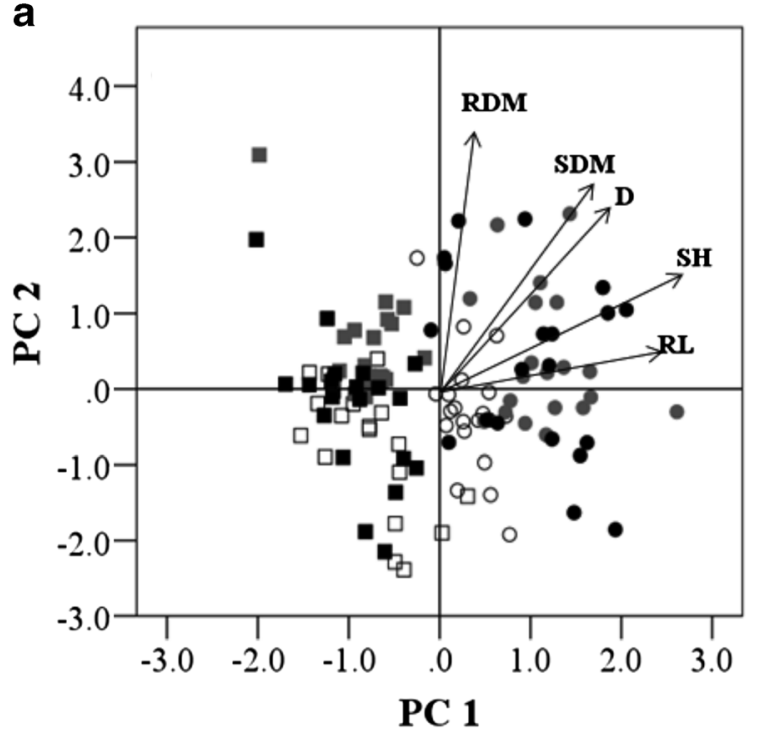

Fig. 4 Principal component analysis, performed by diameter $(D)$, shoot and root dry mass (RDM and SDM), Shoot height (SH), and root length (RL) variables for inoculation in the two nurseries (a) and distribution by

Results presented here showed that in the Buçaco, the inoculum $\mathrm{SgB}$ increased the NUE and PUE in the seedlings when compared to Control and Mix.

$S$. granulatus and P. tinctorius persisted in the root system of inoculated plants, proving to be competitive against nursery contaminant species. It is, however, important to highlight that competitiveness in nursery conditions does not warrant competitiveness in the field against soil-borne forest species. However, such persistence is a desirable characteristic since it brings the advantage of maintaining a mycorrhizal association with a confirmed beneficial effect to the plant (Franco et al. 2014). Bacteria, however, often do not engage such a long-lasting relationship with the host plant. Indeed, several studies have highlighted the frequent inability of PGPB to persist in the root system (Khan et al. 2007; Mosimann et al. 2016) or to maintain the population at a high concentration weeks after inoculation (Teaumroong et al. 2009). Bacterial persistence was not addressed as it would require a time course approach rather than a snapshot sampling at the end of the experiment, which was not within the scope of the present work.

The formation of mycorrhizae in the non-inoculated seedlings was particularly high in Buçaco, with levels of mycorrhization similar to that of the inoculated seedlings, most likely due to the fact that the Buçaco nursery is embedded in a forest. Despite the similar levels of mycorrhization, the quality of the $\mathrm{SgB}$ inoculated seedlings was 2.18-fold higher than the quality of the non-inoculated seedlings (Dickinson quality index). This is most likely because different ECM species or even strains have a different impact on plant performance (Sousa et al. 2012; Oliveira et al. 2012),

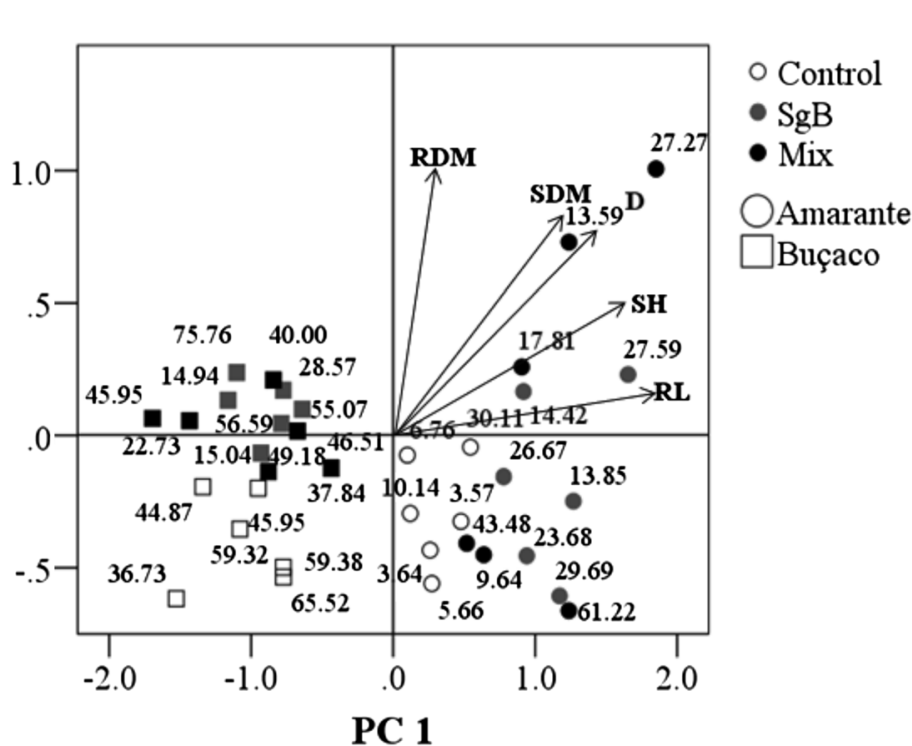

percentage of ectomycorrhizas (b). Component 1 (71\%); component 2 $(15.9 \%)$. The arrows are the vectors, the points are scores, and the numbers in $\mathbf{b}$ are the $\% \mathrm{ECM}$

highlighting the relevance of screening for strains that can become good allies for the host trees, to be used in commercial forest nurseries. Nevertheless, the lack of relationship between plant development and mycorrhizal percentage could also be the consequence of a dominant effect of the inoculated bacteria acting as plant growth promoter and/or a reflexion of different colonization rates by the introduced species (e.g., if $S$. granulatus colonized more extensively the root system than P. tinctorius in Buçaco nursery), and these possibilities have also to be considered. Although the latter hypothesis, regarding the relative percentage of mycorrhization by each species, can be deepened through morphotyping and sequencing of individual root tips, the process is time consuming and prone to human error, and for those reasons, it was not conducted in the present work. The benefit of using bio-inoculants is to give the selected ECM fungi the first-mover advantage. Kennedy et al. (2009) showed that the difference in the timing of colonization is one of the key factors determining the outcome of mycorrhizal competition, with the first colonizers having a strong advantage. In the present study, the performance of inoculated seedlings surpassed that of control plants in both nurseries. Despite the difference in plant growth between Amarante and Buçaco, it is perceived that the advantage of the inoculum would be related to the specificity of the composing species or even to the interaction of these inoculated species with the soil-borne forest species. In Buçaco, where a greater diversity of other species was recorded in the mix and in the non-inoculated control, the inoculum $\mathrm{SgB}$ was more effective in promoting plant growth.

As well as fungi, bacteria strains also differ in their performance on host plants. They can also act on the development of 
mycorrhizal fungi, by modification of the rhizosphere, mediation of the root-fungus process, stimulation of the germination of fungal propagules, and especially enhancement of fungal growth (Dunstan et al. 1998). The ability of Mesorhizobium sp. (isolate 3A12) to act as MHB was evaluated in co-inoculation with Paxillus involutus (Batsch) Fr., which resulted in an increase in the percentage of ECM of Betula pubescens Ehrh (Sousa et al. 2015). Also, it is known that the bacterial concentration may affect the mycorrhizal establishment. Aspray et al. (2006) observed that Paenibacillus sp. and Burkholderia sp. produced contrasting effects on mycorrhiza formation when inoculated at different doses. In this study, despite the different bacterial concentration present in the $\mathrm{SgB}\left(10^{8} \mathrm{CFU} / \mathrm{ml}\right)$ and $\mathrm{Mix}\left(10^{5} \mathrm{CFU} / \mathrm{ml}\right)$ inocula applied, there was no statistical difference in the percentage of mycorrhizal infection. Nevertheless, it can be inferred that in Buçaco, the synergy between S. granulatus + Mesorhizobium sp. promoted a higher quality of the inoculated seedlings, as shown by the Dickson Quality Index.

The Dickson Quality Index is an important indicator of the quality of the seedlings to be transplanted to the field and has been used in several studies (Ritchie 1984; Hunt 1990; Ahmadloo et al. 2012; Trubat et al. 2010; Oliet et al. 2009). The highest values were recorded for the Mix (2.07) in Amarante and the $\operatorname{SgB}(1.86)$ in Buçaco, and these are within the range of those reported by Chirino et al. (2008), for 1-yearold seedlings of $Q$. suber.

The values obtained for the slenderness quotient are within the recommended range (lower than 10 is the recommended standard by Birchler et al. (1998)). In this study, the values were in the range of 3.97 (Mix of Buçaco) and 6.35 ( $\mathrm{SgB}$ of Amarante). Chirino et al. (2008) obtained, for seedlings of Q. suber, SQ between 7.12 and 7.18. Oliet et al. (2005) found values between 6.4 and 9.3 for 1-year-old seedlings of Acacia salicina. These values seem to vary according to the specificity of the species and the site conditions, which has been corroborated by the present study, where the seedlings with the same age and under the same nursery practices, presented significant differences among nurseries; for example, in the case of $\mathrm{SgB}$, the Amarante seedlings were 1.54-fold more robust than in Buçaco.

The nurseries had a great influence on the variation of biometric parameters, whereas the type of inoculation treatment also influenced the nutritional parameters; based on the PCA, made with two components formed from the growth variables, it is clear that plant biomass differed significantly among nurseries. There is a wide range of environmental factors that may account for the different plant development and inoculum efficacy among nurseries, from abiotic (temperature, humidity, solar radiation) and biotic (competition or synergy with resident fungal and bacterial species). According to Dalong et al. (2011), some species are more ecologically adapted to certain locations than others and to obtain maximum benefit from the mycorrhizal association seedlings should be inoculated with fungal symbionts specific to the host and adapted to the environmental conditions of the site. This is particularly important since the nursery environment is abundant in fungal propagules and other microorganisms, which are often aggressive, and only the use of tuned and efficient inoculants can overcome such competition. In the present study, we compared a dual inoculum with a mixture of two fungus and six bacteria. The industrial segment currently has a clear focus on using microbial mixtures, and therefore, it is important to test their efficacy as they are presented commercially. However, using that approach, it is not possible to ascertain whether the effect observed on seedlings is due to bacteria alone, ECM fungus alone, or their combination, as it happened in the present work.

Although this knowledge would be desirable from a scientific and economic point of view, in vitro testing of the fungalbacteria synergy has proven not to be a reliable indicator of their behavior in the presence of the host plant (Rincón et al. 2005), and given that testing all possible microbial combinations is not feasible in practical terms, upstream experiments are required to select the most promising inocula that consistently deliver good performance under different scenarios. In the present work, S. granulatus and Mesorhizobium sp., which were chosen for their individual characteristics, have proven to be a promising inoculum for $Q$. suber, and future work will deepen the role of each microorganism in this partnership.

The replacement of chemical fertilizers by mycorrhizal fungi in the production of containerized seedlings is crucial towards a sustainable environment. While spores may be easier to manage commercially, given their extended shelf life and resistance to a large spectrum of environmental conditions, the use of mycelium has several advantages such as a quicker colonization (representing an advantage over competing fungi) and, most importantly, the possibility to use a specific strain, whereas spores introduce genetic variability. Despite the body of knowledge that exists on the use of microbial inoculants, these products have not yet successfully penetrated the market (Lesueur et al. 2016). Inconsistent results in the field and the discrepancy found between laboratory, nursery, and field studies are some of the reasons that account for this failure (Malusá et al. 2012). There is the need to select specific ECM strains for specific host trees and environments, and it is also important to develop efficient formulations for inocula delivery that ensures market sustainability (i.e., low cost, extended shelf life, storage at room temperature) without compromising product efficiency.

\section{Conclusion}

The seedlings inoculated with the dual inoculum (S. granulatus + Mesorhizobium sp.) showed better results regarding growth 
and plant quality and the fungus persisted in the root system. The different results recorded in Amarante and Buçaco nurseries demonstrated the influence of the environmental conditions on the development of inoculated seedlings, which can increase or decrease the inoculum efficiency. Performance in field trials will be of paramount importance for the confirmation of the potential of nursery inoculation of $Q$. suber.

Acknowledgements Giovania Araujo is grateful for the scholarship supported by CAPES-Brazilian Federal Agency for Support of the Ministry of Education of Brazil. The authors also acknowledge Fundação para a Ciência e a Tecnologia and Fundo Social Europeu (III Quadro Comunitário de Apoio) for the research grants of Nadine R. Sousa (SFRH/BPD/89112/2012) and Miguel Ramos (SFRH/BD/111056/ 2015). The authors would also like to thank Viveiros de Amarante and Viveiros da Mata do Buçaco for their technical support.

Funding This work was supported by Amorim Florestal, S.A., and National Funds from Fundação para a Ciência e a Tecnologia (FCT) through project UID/Multi/50016/2013. Open access was financed by the project NORTE-01-0246-FEDER-000011, supported by the Norte Portugal Regional Operational Programme (NORTE 2020), under the PORTUGAL 2020 Partnership Agreement, through the European Regional Development Fund (ERDF).

Open Access This article is distributed under the terms of the Creative Commons Attribution 4.0 International License (http:// creativecommons.org/licenses/by/4.0/), which permits unrestricted use, distribution, and reproduction in any medium, provided you give appropriate credit to the original author(s) and the source, provide a link to the Creative Commons license, and indicate if changes were made.

\section{References}

Ahemad M, Kibret M (2014) Mechanisms and applications of plant growth promoting rhizobacteria: current perspective. J King Saud Uni Sci 26:1-20. https://doi.org/10.1016/j.jksus.2013.05.001

Ahmadloo F, Tabari M, Yousefzadeh H, Kooch Y, Rahmani A (2012) Effects of soil nutritional status on seedling nursery performance of Arizona cypress (Cupressus arizonica var arizonica Greene) and Medite cypress (Cupressus sempervirens var. horizantalis (Mill.) Gord). African J Plant Sci 6:140-149

Aspray TJ, Jones EE, Whipps JM, Bending GD (2006) Importance of mycorrhization helper bacteria cell density and metabolite localization for the Pinus sylvestris-Lactarius rufus symbiosis. FEMS Microbiol Ecol 56:25-33. https://doi.org/10.1111/j.1574-6941. 2005.00051.x

Azul AM, Sousa JP, Agerer R, Martín MP, Freitas H (2010) Land use practices and ectomycorrhizal fungal communities from oak woodlands dominated by Quercus suber L. considering drought scenarios. Mycorrhiza 20:73-88. https://doi.org/10.1007/s00572-0090261-2

Bhattacharyya PN, Jha DK (2012) Plant growth-promoting rhizobacteria (PGPR): emergence in agriculture. World J Microbiol Biotechnol 28(4):1327-1350. https://doi.org/10.1007/s11274-011-0979-9

Birchler T, Rose RW, Royo A, Pardos M (1998) La planta ideal: revisión del concepto, parámetros definitorios e implementación práctica. Invest Agric Sist Recur For 7:109-121

Brundrett M, Bougher N, Dell B, Grove T, Malajczuk N (1996) Working with mycorrhizas in forestry and agriculture. Pirie Printers, Canberra, pp 173-216
Cairney JW, Chambers SM (2013) Ectomycorrhizal fungi: key genera in profile. Springer, Berlin

Camilo-Alves CSP, Clara MIE, NMC R (2013) Decline of Mediterranean oak trees and its association with Phytophthora cinnamomi: a review. Eur J Forest Res 132:411-432. https://doi.org/10.1007/ s10342-013-0688-Z

Chirino E, Vilagrosa A, Hernández EI, Matos A, Vallejo VR (2008) Effects of a deep container on morpho-functional characteristics and root colonization in Quercus suber L. seedlings for reforestation in Mediterranean climate. For Ecol Manag 256:779-785. https://doi. org/10.1016/j.foreco.2008.05.035

Costa A, Madeira M (2011) Assessment of Mediterranean evergreen oak (Quercus suber L.) woodlands loss. Consequences of climate change effects: a case study at south-western Portugal. In: Proceedings of the "Global Conference on Global Warming". URL: http://www.cge.uevora.pt/ GCGW/presentations/97-127-1RV

Dalong M, Luhe W, Guoting Y, Liqiang M, Chun L (2011) Growth response of Pinus densiflora seedlings inoculated with three indigenous ectomycorrhizal fungi in combination. Braz J Microbiol 42: 1197-1204. https://doi.org/10.1590/S1517-838220110003000045

Dhindwal AS, Lather BPS, Singh J (1991) Efficacy of seed treatment on germination, seedling emergence and vigor of cotton (Gossypium hirsutum) genotypes. Seed Sci Res 19:59-61

Dickie IA, Xu B, Koide RT (2002) Vertical niche differentiation of ectomycorrhizal hyphae in soil as shown by T-RFLP analysis. New Phytol 156:527-535

Dickson A, Leaf AL, Hasuer JF (1960) Quality appraisal of white spruce and white pine seedlings stock in nurseries. Forest Chron 36:10-13. https://doi.org/10.5558/tfc36010-1

Dunstan WA, Malajczuk N, Dell B (1998) Effects of bacteria on mycorrhizal development and growth of container grown Eucalyptus diversicolor F Muell. Seedlings. Plant Soil 201(2):241-249. https://doi.org/10.1023/A:1004329626763

Franco AR, Sousa NR, Ramos MA, Oliveira RS, Castro PML (2014) Diversity and persistence of ectomycorrhizal fungi and their effect on nursery-inoculated Pinus pinaster in a post-fire plantation in northern Portugal. Microb Ecol 68:761-772. https://doi.org/10. 1007/s00248-014-0447-9

Frey-Klett P, Garbaye J, Tarkka M (2007) The mycorrhiza helper bacteria revisited. New Phytol 176:22-36. https://doi.org/10.1111/j.14698137.2007.02191.x

Frey-Klett, Chavatte M, Clausse ML, Courrier S, Le Roux C, Raaijmakers J, Martinotti MG, Pierrat JC, Garbaye J (2005) Blackwell Publishing, Ltd. Ectomycorrhizal symbiosis affects functional diversity of rhizosphere fluorescent pseudomonads

Garcia K, Delaux PM, Cope KR, Ané JM (2015) Molecular signals required for the establishment and maintenance of ectomycorrhizal symbioses. New Phytol 208:79-87. https://doi.org/10.1111/nph. 13423

Hall T (1999) Bioedit: a biological sequence alignment editor and analysis program for windows 95/98/nt. Nucleic Acids Symp Ser 41:9598

Hrynkiewicz K, Baum C (2011) The potential of rhizosphere microorganisms to promote the plant growth in disturbed soils. In: Malik A, Groham E (ed) Environmental protection strategies for sustainable development. Springer Science Business Media BV Inc Torun, pp $35-64$

Hunt G (1990) Effect of controlled-release fertilizers on formation of mycorrhizae in container-grown Engelmann spruce. Tree Improvement, Forest Service, British Columbia, 3: 6-8

Khan MS, Zaidi A, Wani PA (2007) Role of phosphate solubilizing microorganisms in sustainable agriculture - a review. Agron Sustain Dev 27:29-43. https://doi.org/10.1051/agro:2006011 
Kennedy PG, Peay KG, Bruns TD (2009) Root tip competition among ectomycorrhizal fungi: are priority effects a rule or an exception? Ecology 90:2098-2107. https://doi.org/10.1890/08-1291.1

Lesueur D, Deaker R, Herrmann L, Jansa J (2016) The production and potential of biofertilizers to improve crop yields. In book: Bioformulations: for Sustainable Agriculture, pp 71-92. doi: https://doi.org/10.1007/978-81-322-2779-3_4

Malusá E, Sas-Paszt L, Ciesielska J (2012) Technologies for beneficial microorganisms inocula used as biofertilizers. Sci World J 491206: 1-12. https://doi.org/10.1100/2012/491206

Moeller HV, Peay KG, Fukami T (2014) Ectomycorrhizal fungal traits reflect environmental conditions along a coastal California edaphic gradient. FEMS Microbiol Ecol 87:797-806. https://doi.org/10. 1111/1574-6941.12265

Morris MH, Pérez-Pérez MA, Smith ME, Bledsoe CS (2008) Multiple species of ectomycorrhizal fungi are frequently detected on individual oak root tips in a tropical cloud forest. Mycorrhiza 18:375-383. https://doi.org/10.1007/s00572-008-0186-1

Mosimann C, Oberhänsli T, Ziegler D, Nassal D, Kandeler E, Boller T, Mäder P, Thonar C (2016) Tracing of two pseudomonas strains in the root and rhizoplane of maize, as related to their plant growthpromoting effect in contrasting soils. Front Microbiol 7:2150. https://doi.org/10.3389/fmicb.2016.02150

Novozamsky I, Houba VJG, Van Eck R, Van Vark W (1983) A novel digestion technique for multi-element plant analysis. Comm Soil Sci Plant Anal 14: 239-248, DOI: 10.1080/ 00103628309367359

Oliet JA, Planelles R, Artero F, Jacobs DF (2005) Nursery fertilization and tree shelters affect long-term field response of Acacia salicina Lindl. planted in Mediterranean semiarid conditions. For Ecol Manag 215:339-351. https://doi.org/10.1016/j.foreco.2005.05.024

Oliet JA, Planelles R, Artero F, Valverde R, Jacobs DF, Segura ML (2009) Field performance of $P$. halepensis planted in Mediterranean arid conditions: relative influence of seedling morphology and mineral nutrition. New For 37:313-331. https://doi.org/10.1007/s11056008-9126-3

Oliveira RS, Franco AR, Castro PML (2012) Combined use of Pinus pinaster plus and inoculation with selected ectomycorrhizal fungi as an ecotechnology to improve plant performance. Ecol Eng 43:95103. https://doi.org/10.1016/j.ecoleng.2012.01.021

Owen D, Williams AP, Griffith GW, Withers PJA (2014) Use of commercial bio-inoculants to increase agricultural production through improved phosphorus acquisition. App Soil. Ecol 86:41-54

Pereira SIA, Barbosa L, Castro PML (2014) Rhizobacteria isolated from a metal-polluted area enhance plant growth in zinc and cadmiumcontaminated soil. Int J Environ Sci Technol 12:2127-2142. https://doi.org/10.1007/s13762-014-0614-Z

Perrin R, Garbaye J (1983) Influence of ectomycorrhizae on infectivity of pythium-infested soils and substrates. Plant Soil 71:345-351. https://doi.org/10.1007/BF02182674

Quoreshi AM, Khasa DP (2008) Effectiveness of mycorrhizal inoculation in the nursery on root colonization, growth, and nutrient uptake of aspen and balsam poplar. Biomass Bioenergy 32:381-391. https:// doi.org/10.1016/j.biombioe.2007.10.010
Rincón A, Ruiz-Díez B, García-Fraile S, García JA, Fernández-Pascual M, Pueyo JJ, de Felipe MR (2005) Colonisation of Pinus halepensis roots by Pseudomonas fluorescens and interaction with the ectomycorrhizal fungus Suillus granulatus. FEMS Microbiol Ecol 51(3):303-311

Ritchie GA (1984) Assessing seedling quality. In: Duryea ML, Landis TD (eds) Forest nursery manual: production of Bareroot seedlings. Martines Nijhoff/Dr W Junk Publishers, Hague/Boston/Lancaster, pp 243-259. https://doi.org/10.1007/978-94-009-6110-4_23

Sebastiana M, Pereira VT, Alcântara A, Pais M, Silva A (2013) Ectomycorrhizal inoculation with Pisolithus tinctorius increases the performance of Quercus suber L. (cork oak) nursery and field seedlings. New For 2013:44-949. https://doi.org/10.1007/s11056013-9386-4

Siddiqi MY, Glass ADM (1981) Utilization index: a modified approach to the estimation and comparison of nutrient utilization efficiency in plants. J Plant Nutr 4:289-302. https://doi.org/10.1080/ 01904168109362919

Sousa NR, Ramos MA, Franco AR, Oliveira RS, Castro PML (2012) Mycorrhizal symbiosis affected by different genotypes of Pinus pinaster. Plant Soil 359:245-253. https://doi.org/10.1007/s11104012-1196-5

Sousa NR, Franco AR, Oliveira RS, Castro PML (2014) Reclamation of an abandoned burned forest using ectomycorrhizal inoculated Quercus rubra. For Ecol Manag 320:50-55. https://doi.org/10. 1016/j.foreco.2014.02.033

Sousa NR, Franco AR, Ramos MA, Oliveira RS, Castro PML (2015) The response of Betula pubescens to inoculation with an ectomycorrhizal fungus and a plant growth promoting bacterium is substrate-dependent. Ecol Eng 81:439-443. https://doi.org/10.1016/ j.ecoleng.2015.04.024

Taub DR, Wang XZ (2008) Why are nitrogen concentrations in plant tissues lower under elevated $\mathrm{CO}_{2}$ ? A critical examination of the hypotheses. J Integr Plant Biol 50:1365-1374. https://doi.org/10. 1111/j.1744-7909.2008.00754.x

Teaumroong N, Wanapu C, Chankum Y, Arjharn W, Sang-Arthit S, Teaimthaisong K, Boonkerd N (2009) Production and application of bioorganic fertilizers for organic farming systems in Thailand: a case study. Microbes at work: from wastes to Resources: 293

Thompson BE (1985) Seedling morphological evaluation: what you can tell by looking. In: Duryea ML (ed) Evaluating seedling quality: principles, procedures, and predictive ability of major tests. Oregon State University, Corvallis, pp 59-71

Trappe JM (1977) Selection of fungi for ectomycorrhizal inoculation in nurseries. Annu Rev Phytopathol 15:203-222. https://doi.org/10. 1146/annurev.py.15.090177.001223

Trubat R, Cortina J, Vilagrosa A (2010) Nursery fertilization affects seedling traits but not field performance in Quercus suber L. J of Arid Environ 74:491-497. https://doi.org/10.1016/j.jaridenv.2009.10. 007

Walinga I, Van Vark W, Houba VJG, van der Lee JJ (1989) Plant analysis procedures (soil and plant analysis, part 7). Wageningen, Syllabus, $p$ 264 